\title{
A study of persons aged 65 and over in the Leeds Metropolitan District
}

\author{
H. MCDONNELL, A. F. LONG ${ }^{1}$ B. J. HARRISON, AND C. OLDMAN
}

From the Department of Community Medicine and General Practice and the ${ }^{1}$ Nuffield Centre for Health Services Studies, University of Leeds

SUMMARY A study of the elderly living in the community and in institutional care in the Leeds Metropolitan District is outlined. Four populations of persons aged 65 and over were examined: those living in their own homes; in sheltered housing; in social services aged persons' hostels (Part III accommodation); and in hospitals. Findings on one key concept-coping ability-are discussed. Those living in their own homes were most able to cope. Many living in institutions were well able to cope in the community according to the criteria of mobility and functional ability. The relationship between age, morbidity, and coping ability were examined. Women were more likely to report the presence of a long-term illness than men. Housebound respondents in the community were twice as likely to be suffering from non-traumatic locomotor disorders, eyesight disorders, and cerebrovascular disease than respondents in the community sample taken as a whole.

Survival and age at death in Britain have both increased dramatically in this century. At present $15 \%$ of the population of England and Wales are aged 65 or over, and one in every 100 is aged 85 or over. By the year 2000 , these figures will be $14 \%$ and one in 65. Policy-makers in the health and social services are becoming increasingly aware of this growing group of elderly persons and their problems, and their concern has been reflected in the policy statements and consultative documents of recent years (Department of Health and Social Security, $1976 ; 1977 ; 1978)$. Much research on policy-making has been undertaken, generally descriptive, and focused on the elderly living in particular locations. Recent examples are Hunt's survey of people aged 65 and over living in the community (Hunt, 1978) and Abrams's study of people aged 75 and over (Abrams, 1978). The former is a straight reporting exercise; the latter has been used to make policy statements about services for the elderly.

This study examined the elderly living in the community and in institutions. It arose from a concern over the lack of local information available for planning health and social services for the elderly in Leeds. As a first step, a problem-orientated survey was launched within the Leeds Metropolitan District, funded from joint financing available to the local authority social services from the Area Health Authority (Teaching), to identify the needs of the elderly and the health and social services' responses.
Previous work has not taken account of the elderly in all locations. This study was focused on four possible ones-their own homes, sheltered housing, aged persons' hostels (Part III accommodation), and hospitals. The overall aim was to establish a descriptive baseline upon which further studies would be built. The intention is to evaluate alternative schemes for supporting the elderly in the community and to examine measures to prevent, for example, fracture of the neck of the femur.

The overall aims of the survey were to provide empirical data and to help formulate hypotheses for later study. The objectives were:

1. To identify the ways in which old people were living in their own homes.

2. To determine whether there were any identifiable differences between those living in the community and elsewhere.

3. To explore how health and social services affected the ability of old people to cope.

4. To examine those old people currently in institutional care in relation to their life at home before admission and their current ability to cope outside such accommodation.

In other words, the aim was to describe the pattern and the circumstances surrounding the old persons' lives and to formulate some tentative conclusions on the appropriateness of the health and social services' response and provision. 


\section{Method and materials}

Because the day-to-day experiences of those living in the community and those living in care were expected to differ, two complementary questionnaires were drawn up. The first questionnaire was designed for the sheltered housing and 'at home' samples, and it related solely to the respondent's own view of the past and present. This was a postal questionnaire. The second questionnaire was produced for the elderly in hospital and Part III accommodation. It was administered by interviewers who were the relevant professionals: that is, a ward sister or nurse, or the home's warden or care assistant. It related both to the respondent's own view of the past and present, and the interviewer's perceptions of the present situation.

The questionnaires were designed to acquire data on personal characteristics, physical environment, contact with friends, relatives, and neighbours, contact with health and social services, functional ability, mobility, and health (current and longstanding). The questionnaire for the 'at home' and sheltered housing samples asked for information on domestic activities. The questionnaire for the Part III and hospital samples also asked for information on the respondent's capability for self-care and mobility, and on the possibility of discharge or transfer.

The survey was intended to clarify a key concept-coping ability-so that the statement 'an elderly person can be said to be coping by the very fact that he lives in the community' could be made more specific and subjected to a functional definition. Broader questions were then explored, such as whether those in care were unable to cope in the community.

The overall concept of 'need' was defined in terms of 'coping ability'. For example, the less a person was able to copd at home, the more he or she was in need. 'Coping ability' had three components:

1. Mobility measured by the ability to get out of bed, around the house, and out of the house.

2. Functional ability measured by such activities as feeding, using the wc, and having a bath.

3. Domestic activities measured by such items as washing, cleaning, and cooking.

Because of the divergent day-to-day experiences of the four samples, identical questions on these dimensions were not asked. Abilities were examined individually. Scales of mobility and functional ability were also drawn up. Accordingly, if an old person said that he was unable to get out of bed, he would be classified as having low mobility, thus implying a low ability to cope.
Table 1 The three stages of the sampling procedure

\begin{tabular}{lrc}
\hline STAGE 1: To identify the population aged over 65 \\
\hline Stage of sampling & Households & Proportion seen \\
\hline Random sample 1 in 20 & 13181 & $5 \%$ of total \\
Households contacted & 10980 & $86 \%$ of sample \\
Households with persons $65+$ & 4131 & $38 \%$ of households contacted \\
\hline
\end{tabular}

STAGE 2: To collect information on those aged $65+$

\begin{tabular}{lllll}
\hline Group & Questionnaire & Sampling & Numbers & $\begin{array}{l}\text { Proportion } \\
\text { seen }\end{array}$ \\
\hline At home & At home & 1 in 20 & 2815 & $68 \%$ \\
Sheltered housing & At home & 1 in 9 & 288 & $88 \%$ \\
Part III & In care & 1 in 10 & 182 & $100 \%$ \\
Hospitals & In care & 1 in 10 & 201 & $100 \%$ \\
\hline
\end{tabular}

STAGE 3: To check on responders and non-responders at home

\begin{tabular}{lllll}
\hline Group & Questionnaire & Sampling & Numbers & $\begin{array}{l}\text { Proportion } \\
\text { seen }\end{array}$ \\
\hline Responders & At home & 1 in 20 & 191 & $84 \%$ \\
Non-responders & At home & 1 in 3 & 116 & $52 \%$ \\
\hline
\end{tabular}

The main survey was carried out in the perioळ May-June 1977. The sampling frame for the a $a$ home' sample was the February 1977 electorah register for Leeds Metropolitan District. A one in 200 sample of householders was extracted. To each of the resulting 13181 households a letter was sent asking if anyone in the household was aged 65 or over. Eighty-six per cent of the householders responded to this letter. A questionnaire was sent to each old person living in the household. The response rate was $68 \%$. The other three samples were drawn from health and social service records by the relevant professionals (nurses or wardens) using random number tables. In sheltered housing a one in nine sample was drawn with a response rate of $88 \%$. In the Part III and hospital groups a one in 10 sample was drawn, subject to the criterion that the respondent had been in such accommodation for less than two years.* In July-August 1977 a subsample of the responding 'at home' group were interviewed by health visitors as a check on the validity of the responses. A sample of non-responders was also drawn and interviewed by health visitors to determine their characteristics. The response rates were $84 \%$ and $52 \%$ respectively. Table 1 summarises the three stages of the sampling procedure. ${ }^{* *}$ Checks -A limit of two years was fixed because of problems about the respondents
being able accurately to recall life at home before admission. Separate
studies need to be made of those in long-term institutional care.
"In the future such a sampling frame to identify first where old people live
may be unnecessary, because it is likely that a master person index will be
drawn up in Leeds. 
on the representativeness of the 'at home' sample were carried out at Stage 1 and at Stage 2 in the sampling procedure. Comparison was made with the 1971 census information and updated figures (Office of Population Censuses and Surveys, 1977).

\section{Results}

\section{REPRESENTATIVENESS}

The sampling frame for old people living in their own homes generated at Stage 1 (Table 1) was representative of the Leeds Metropolitan District population aged 65 and over in terms of both total size and age and sex structure. However, looking at the sample achieved at Stage 2 (Table 1), fewer people aged up to 70 and more people aged 70 or over completed the questionnaire than would be expected given the age and sex structure of the sampling frame.* In some ways the bias was useful, in that ill-health and need for support are features of older life. Thus it may be easier to see the role and support provided by health and social services, families, and friends. In the broader context it is necessary to note this bias towards the 'older' elderly in interpreting the results. The data from the subsample of the responding 'at home' group and from the check on non-responders indicated that there was little problem of bias from these two sources.

Table 2 Key demographic features

\begin{tabular}{|c|c|c|c|c|c|}
\hline & \multirow[b]{2}{*}{ At home } & \multirow{2}{*}{$\begin{array}{l}\text { Sheltered } \\
\text { housing }\end{array}$} & \multicolumn{2}{|c|}{ Hospital } & \multirow[b]{2}{*}{ Part III } \\
\hline & & & Acute & Long-stay & \\
\hline \multicolumn{6}{|l|}{ SEX } \\
\hline $\begin{array}{l}\text { \% Males } \\
\text { \% Females }\end{array}$ & $\begin{array}{l}41 \\
59\end{array}$ & $\begin{array}{l}29 \\
71\end{array}$ & $\begin{array}{l}47 \\
54\end{array}$ & $\begin{array}{l}33 \\
67\end{array}$ & $\begin{array}{l}22 \\
78\end{array}$ \\
\hline $\begin{array}{l}\text { AGE } \\
\text { Median age }\end{array}$ & 72 & 77 & 77 & 80 & 82 \\
\hline $\begin{array}{l}\text { STATUS } \\
\text { \% Single } \\
\text { \% Married } \\
\text { \% Widowed, } \\
\text { separated, } \\
\text { or divorced } \\
\text { \% Living alone }\end{array}$ & $\begin{array}{l}10 \\
48 \\
42\end{array}$ & $\begin{array}{l}10 \\
21 \\
68\end{array}$ & $\begin{array}{l}10 \\
45 \\
45\end{array}$ & $\begin{array}{r}7 \\
22 \\
71\end{array}$ & $\begin{array}{r}16 \\
2 \\
82\end{array}$ \\
\hline
\end{tabular}

tLiving alone before admission.

\section{DEMOGRAPHIC FEATURES OF THE FOUR}

SAMPLES

Table 2 summarises data on the age, sex, marital status, and proportion living alone in the four samples. The 'at home' and acute hospital samples had a higher ratio of females to males than the other samples. The 'at home' sample was younger, with a

\footnotetext{
*The difference is significant at the $5 \%$ but not at the $1 \%$ level.
}

median age of 72 , and the Part III sample was the oldest, with a median age of 82 . There were more widowed, separated, or divorced respondents in the sheltered housing, Part III, and long-stay hospital samples. The 'at home' sample had the lowest percentage of people living alone (38\%); the Part III and sheltered housing samples contained the highest percentage $-69 \%$ and $77 \%$ respectively.

\section{COPING ABILITY}

Data on mobility (Table 3 ) showed that very few of the 'at home' and sheltered housing respondents required help to get out of bed-2\% and $4 \%$ respectively. However, $16 \%$ of the Part III respondents, $32 \%$ of the acute hospital respondents, and $62 \%$ of the long-stay hospital respondents required assistance. Comparing the 'at home' and sheltered housing respondents, the only difference was in relation to assistance for going outside the home. Fourteen per cent of the 'at home' respondents required help compared with $30 \%$ of the sheltered housing respondents. For the Part III and the hospital respondents, the former were the more mobile and the long-stay hospital respondents the least mobile.

For functional ability (Table 4) a similar trend is apparent. The 'at home' sample was the most able, the hospital sample the least. Those items causing the greatest difficulty to all groups were: going up and down stairs; having a bath; and cutting nails. The long-stay hospital group experienced considerable difficulties for all items.

Table 3 Mobility among the four samples

\begin{tabular}{lccllll}
\hline & & & & \multicolumn{2}{l}{ Hospital } \\
\cline { 5 - 6 } & $\begin{array}{l}\text { At home } \\
\text { Help needed }\end{array}$ & $\begin{array}{l}\text { Sheltered } \\
\text { housing } \\
\%\end{array}$ & $\begin{array}{l}\text { Part III } \\
\text { Acute }\end{array}$ & $\begin{array}{l}\text { Long-stay } \\
\%\end{array}$ \\
\hline Out of bed & 2 & 4 & 16 & 32 & 62 \\
$\begin{array}{l}\text { Out of chair } \\
\text { Walking }\end{array}$ & $*$ & $*$ & 10 & 31 & 56 \\
$\begin{array}{l}\text { Around the house } \\
\text { To go outside }\end{array}$ & 3 & $*$ & 16 & 31 & 57 \\
\hline
\end{tabular}

- Data were not collected on these specific questions for the respective groups.

Table 4 Functional ability among the four samples

\begin{tabular}{lllllll}
\hline & & & & \multicolumn{2}{l}{ Hospital } \\
\cline { 5 - 7 } \cline { 4 - 6 } Help needed with & $\begin{array}{l}\text { At home } \\
\%\end{array}$ & $\begin{array}{l}\text { Sheltered } \\
\text { housing } \\
\%\end{array}$ & $\begin{array}{l}\text { Part III } \\
\%\end{array}$ & $\begin{array}{l}\text { Acute } \\
\%\end{array}$ & $\begin{array}{l}\text { Long-stay } \\
\%\end{array}$ \\
\hline Feeding & 1 & 2 & 3 & 1 & 11 \\
Going to the WC & 1 & 2 & 9 & 23 & 60 \\
Dressing & 3 & 4 & 17 & 18 & 51 \\
Washing & 1 & 1 & 6 & 12 & 34 \\
Going up/down stairs & 5 & 4 & 56 & 35 & 72 \\
Having a bath & 10 & 16 & 85 & 49 & 92 \\
Cutting nails & 13 & 22 & 75 & 35 & 86 \\
\hline
\end{tabular}


Table 5 compares the functional ability of the 'at home' and sheltered housing groups in scalar form. Fourteen per cent of the 'at home' and $20 \%$ of the sheltered housing respondents required help with one or more functional activities.

Table 6 provides information on the help required with domestic activities for the 'at home' and sheltered housing samples. The 'at home' respondents were less likely to require assistance than the sheltered housing respondents. Cooking appeared to be the least problematic activity. Of the 'at home' sample, $38 \%$ required help with one or more domestic activity, compared with $68 \%$ of sheltered housing respondents.

Table 5 Functional ability for the 'at home' and sheltered housing samples

\begin{tabular}{lll}
\hline Functional ability & $\begin{array}{l}\text { At home } \\
\%\end{array}$ & $\begin{array}{l}\text { Sheltered housing } \\
\%\end{array}$ \\
\hline No help needed with any activity & 86 & 80 \\
Help needed with only one activity & 8 & 14 \\
Help needed with more than one activity & 6 & 6 \\
\hline
\end{tabular}

Table 6 Domestic activities for the 'at home' and sheltered housing samples

\begin{tabular}{lrl}
\hline Help needed with: & $\begin{array}{l}\text { At home } \\
\%\end{array}$ & $\begin{array}{l}\text { Sheltered housing } \\
\%\end{array}$ \\
\hline Shopping & 27 & 46 \\
Cooking & 3 & 10 \\
Washing & 24 & 43 \\
Cleaning & 24 & 47 \\
& & \\
One or more items & & \\
Three or more items & 38 & 68 \\
\hline
\end{tabular}

4. DEMOGRAPHIC FACTORS AND COPING ABILITY FOR THE 'AT HOME' SAMPLE

Females aged 75 and over were less mobile than females aged under 75 . There was no difference for males (Table 7). Looking at data on functional ability by age and sex, those aged over 75 required more help with functional activities than those aged under 75 , and older men were less dependent than older women. Those living alone required less help than those living with someone else.

5. THE PREVALENCE OF ILL-HEALTH IN THE FOUR SAMPLES

The percentage of respondents suffering from a long-term illness varied from $36 \%$ of the acute hospital sample to $74 \%$ of the long-stay hospital sample. The illnesses most frequently mentioned were: non-traumatic locomotor disorders; heart
Table 7 Mobility levels

\begin{tabular}{|c|c|c|c|c|c|}
\hline & \multirow[b]{2}{*}{$\begin{array}{l}\text { Age group } \\
\text { (years) }\end{array}$} & \multicolumn{4}{|c|}{ Respondents at various levels of mobility } \\
\hline & & $\begin{array}{l}\text { Least } \\
\text { mobile } \\
\%\end{array}$ & $\begin{array}{l}\text { Less } \\
\text { mobile } \\
\%\end{array}$ & $\begin{array}{l}\text { More } \\
\text { mobile } \\
\%\end{array}$ & $\begin{array}{l}\text { Fully } \\
\text { mobile } \\
\%\end{array}$ \\
\hline Males & $\begin{array}{l}65-74 \\
75+\end{array}$ & - & $\begin{array}{l}1 \\
3\end{array}$ & $\begin{array}{r}7 \\
11\end{array}$ & $\begin{array}{l}92 \\
86\end{array}$ \\
\hline Females & $\begin{array}{l}65-74 \\
75+\end{array}$ & - & $\begin{array}{l}1 \\
4\end{array}$ & $\begin{array}{r}7 \\
27\end{array}$ & $\begin{array}{l}92 \\
68\end{array}$ \\
\hline
\end{tabular}

disease; eyesight disorders; cerebrovascular disease; and respiratory infections. The same illnesses were also listed as causing recent ill-health. More respondents in sheltered housing and Part III accommodation had non-traumatic locomotor disorders and more respondents in sheltered housing suffered from heart disease. Non-traumatic locomotor disorders were the single most common disorder affecting the elderly, irrespective of location.

\section{LONG-TERM ILLNESSES AND COPING} ABILITY

Table 8 provides data on the effect of long-term illnesses on coping ability, using a scale of mobility and functional ability. Items included in the scaloe were: whether help was needed in getting around the house, cutting nails, having a bath, going up an down stairs, and doing the shopping. The data for the Part III and hospital samples relate to the respondents' own statements concerning their activities before admission. The comparison is between the average capability for performing a task for a respondent with a chronic illness and the average capability of respondents in the whole of that sample. The debilitating effect of cerebrovascular disease was apparent. The overall coping abilities of the respondents in sheltered housing and 'at home' were more severely affected than those of respondents in hospital or Part III accommodation.

Table 8 The effect of long-term illness on mobility and functional activity

\begin{tabular}{lllll}
\hline & \multicolumn{3}{l}{ Activity change } & \\
\cline { 2 - 5 } Illnesses & Home & Sheltered & Hospital & Part III \\
\hline Non-traumatic locomotor disorder & $*$ & $*$ & $*$ & $*$ \\
Heart disease & $*$ & $*$ & $*$ & $*$ \\
Eyesight problems & $*$ & $*$ & $*$ & $*$ \\
Cerebrovascular disease & $*$ & $*$ & $*$ & $*$ \\
Respiratory infection & $*$ & $*$ & 0 & 0 \\
\hline
\end{tabular}

Key:

0 more able to cope than respective sample

* two times less able to cope than respective sample

* four times less able to cope than respective sample. 
7. PREVALENCE OF ILL-HEALTH AMONG THE HOUSEBOUND

Respondents from the sheltered housing and 'at home' samples who were housebound were more likely to have been ill recently. Sixty-six per cent of the housebound 'at home' respondents and 53\% of the housebound sheltered housing respondents had been ill recently, compared with $32 \%$ and $42 \%$ respectively of the total samples. Looking at long-term illness among the housebound for the four groups (Tables 9 and 10), a clear relationship was apparent between being housebound and having a long-term illness. Data for the Part III and hospital groups relate to the period before admission. For example, $88 \%$ of the housebound 'at home' suffered from a long-term illness compared with $56 \%$ of the total 'at home' sample.

Table 9 Long-term illness among the housebound: 'at home' and sheltered housing samples

\begin{tabular}{|c|c|c|c|c|}
\hline \multirow[b]{2}{*}{ Long-term illness } & \multicolumn{2}{|c|}{$\begin{array}{l}\text { Housebound } \\
\text { respondents }\end{array}$} & \multicolumn{2}{|c|}{$\begin{array}{l}\text { All } \\
\text { respondents }\end{array}$} \\
\hline & $\begin{array}{l}\text { At home } \\
\%\end{array}$ & $\begin{array}{l}\text { Sheltered } \\
\%\end{array}$ & $\begin{array}{l}\text { At home } \\
\%\end{array}$ & $\begin{array}{l}\text { Sheltered } \\
\%\end{array}$ \\
\hline \multicolumn{5}{|l|}{ Non-traumatic locomotor } \\
\hline Heart disease & 18 & 19 & 11 & 16 \\
\hline Eyesight problems & 14 & 7 & 5 & 5 \\
\hline Cerebrovascular disease & 7 & 5 & 2 & 2 \\
\hline Respiratory disorders & 8 & 15 & 6 & 9 \\
\hline
\end{tabular}

No long-term illness

$\begin{array}{llll}12 & 17 & 44 & 37\end{array}$

Table 10 Long-term illness among the housebound: Part III and hospital samples

\begin{tabular}{|c|c|c|c|c|}
\hline \multirow[b]{2}{*}{ Long-term illness } & \multicolumn{2}{|c|}{$\begin{array}{l}\text { Housebound } \dagger \\
\text { respondents }\end{array}$} & \multicolumn{2}{|c|}{$\begin{array}{l}A l l \\
\text { respondents }\end{array}$} \\
\hline & $\begin{array}{l}\text { Part III } \\
\%\end{array}$ & $\begin{array}{l}\text { Hospital } \\
\%\end{array}$ & $\begin{array}{l}\text { Part III } \\
\%\end{array}$ & $\begin{array}{l}\text { Hospital } \\
\%\end{array}$ \\
\hline $\begin{array}{l}\text { Non-traumatic locomotor } \\
\text { disorders } \\
\text { Heart disease } \\
\text { Eyesight problems } \\
\text { Cerebrovascular disease } \\
\text { Respiratory infections } \\
\text { Other neurological conditions }\end{array}$ & $\begin{array}{r}42 \\
10 \\
8 \\
5 \\
8 \\
8\end{array}$ & $\begin{array}{r}44 \\
9 \\
11 \\
11 \\
2 \\
4\end{array}$ & $\begin{array}{r}29 \\
10 \\
9 \\
5 \\
8 \\
3\end{array}$ & $\begin{array}{r}16 \\
9 \\
6 \\
8 \\
6 \\
3\end{array}$ \\
\hline No long-term illness & 20 & 29 & 28 & 44 \\
\hline
\end{tabular}

† Housebound before admission to Part III or hospital care.

8. THE DIFFERENTIAL RESPONSE OF MALES AND FEMALES IN REPORTING LONG-TERM ILLNESS

Significantly more females than males reported that they suffered from a long-term illness $(P<0 \cdot 05)$.
This situation cannot be accounted for by a relationship with age. More females said they had been experiencing non-traumatic locomotor disorders and eyesight disorders, while a greater percentage of males in all four samples reported respiratory infections.

\section{SUPPORT}

The majority of the sheltered housing and 'at home' respondents who had to stay in bed all day were cared for by their spouses. Spouse and immediate family were the most frequently mentioned means of support. The least mobile were most frequently cared for by their spouses. Table 11 provides additional data about informal help given in performing functional activities (by relatives, neighbours and friends) and formal help (by health and social services personnel). Data for the Part III and hospital groups apply to help before admission. Sheltered housing respondents received more formal support and Part III respondents received an equal amount of formal and informal support. Fifty-four per cent of Part III respondents had previously had assistance from home helps and $26 \%$ from meals on wheels. Thirty-nine per cent of sheltered housing respondents were receiving assistance from home helps and $11 \%$ from meals on wheels.

Table11 Ratio of informal to formal support for functional ability

\begin{tabular}{ll}
\hline Sample & Ratio \\
\hline At home & $2: 1$ \\
Sheltered housing & $2: 3$ \\
Part III & $1: 1$ \\
Hospital (acute) (long-stay) & $2: 1$ \\
\hline
\end{tabular}

\section{Discussion}

It is evident that data on functional ability provided the most comprehensive comparison between the four samples. A higher percentage of the 'at home' respondents were most able to cope; the sheltered housing respondents were less mobile and more likely to require help in carrying out functional activities. The Part III and hospital groups were less able to cope, and this was perhaps one reason for their current location. However, on the criteria of mobility and functional ability, there were people living in Part III and in hospital who could cope in the community.

There were, therefore, some respondents in each location who were able to cope and some who were not. The question of how the less able remained in the community is clearly an important one to answer. Information was collected in the survey only on the 
quantity, not the quality, of support provided. Someone who is very dependent on one person may be no worse off than someone with several people on whom to depend unless something happens to remove the support of that one person.

Respondents in sheltered housing and Part III accommodation were most likely to be, or to have been, assisted by the formal services. However, Part III respondents had been taken into care, whereas sheltered housing respondents remained within the community, albeit a sheltered community. Several explanations are possible. Firstly, the sheltered housing respondents received more of the informal type of help (certainly they were more likely to be visited more frequently than Part III respondents). Secondly, assistance from the health and social services was given too late to Part III respondents, who were already less able to cope than sheltered housing respondents. (Sheltered housing respondents were younger than Part III respondents). Thirdly, the combination of sheltered housing with assistance from health and social services was more effective than the maintenance of an old person in his or her own home with such support.

Coping ability is clearly affected by many factors, and the foremost of these is the health of the old person. If an old person has a long-term illness, one would expect him or her to be less able to cope, and more likely to require, if not to be receiving, considerable help from health and social services.

A generally high rate of morbidity was observed. More than $50 \%$ of respondents from each of the four samples suffered from some form of long-term illness. Respondents with a long-term illness in the 'at home' and sheltered housing groups were less able to cope than those not suffering from a long-term illness. This was also true of the housebound respondents. The housebound were more likely to be suffering from a long-term illness. The illnesses most prevalent among the elderly occurred most frequently among the housebound. The prevalence of non-traumatic locomotor disorders in the housebound respondents was twice that in the whole 'at home' sample.

The initial survey carried out in the Leeds Metropolitan District gave limited information on how people were coping. Several issues need clarification: (1) It has long been known that females live longer than males. Females are also more likely to report that they suffer from a long-term illness. Can it then be said that male survivors are more healthy than female survivors? (2) Why are one set of respondents with a low level of coping ability living in the community and another set with a similar level of coping ability living in institutions? The answer must be, to some extent, independent of both mobility and morbidity. Socioeconomic factors and the availability of support will be significant. (3) What is the link between a person's coping ability before and after admission to an institution? This raises the question of whether the move to institutional care was desirable and appropriate, and whether it is possible to identify the medical and social events that may cause a person to become housebound, in which case it might also be possible to prevent the onset of a crisis and the resultant move to institutional care.

There is a need for a longitudinal study to try to answer these questions, to investigate the components of functional deterioration with age, and to determine alternative models of intervention and rehabilitation. The extensive morbidity and its debilitating effect can be treated in two ways. One approach would be to screen regularly for early signs and symptoms of disease from middle age upwards. Prompt medical attention and continuing care may alleviate some chronic conditions. A separate approach would be to provide assistance from both medical and social workers to the housebound. Aid could be given with medical problems and with practical problems. Additional support for the elderly person and his or her family might enable that person to remain in the community.

\section{Conclusion}

The findings on health and coping ability in the 1977 Leeds survey of the elderly confirm earlier findings.

1. Over $50 \%$ of all respondents from the four samples suffered from some form of long-term illness. The most common illness, non-traumatic locomotor disorders, affected $19 \%$ of the elderly in the community.

2. Old people living in their own homes were most able to cope in their own homes. They received more support from relatives and friends than from health and social services.

3. The respondents in sheltered housing were also well able to cope in their own homes but health and social services played a very important part in maintaining them in the community.

4. Although hospital and Part III respondents were less able to cope than the 'at home' and sheltered housing groups, there were those in care who were able to cope on the criteria of mobility and functional ability. The important questions remaining to be answered are whether they can actually cope, what supporting services are required, and how to rehabilitate them from institutional care in the first place. 
5. There were people in each sample who had difficulty in coping. Some of those living in their own homes required considerable support to remain there.

6. Of all four samples, those in the 'at home' sample who suffered a long-term illness were shown to be the least mobile and least capable. The long-term illnesses causing greatest debility were cerebrovascular disease, non-traumatic locomotor disorders, and eyesight problems.

7. Significantly more females than males reported that they suffered from a long-term illness.

We thank the many people who took part in the project for their help and encouragement.

This project was financed by a grant to the Social Services Department of the Leeds Metropolitan District by the Leeds Area Health Authority (Teaching).
Reprints from Dr. H. McDonnell, Department of Community Medicine and General Practice, University of Leeds, 32 Hyde Terrace, Leeds LS2 9LN.

\section{References}

Abrams, M. (1978). Beyond Three Score and Ten; A First Report Survey of the Elderly. Age Concern Publications: London.

Department of Health and Social Security (1976). Priorities for Health and Personal Social Services in England: $A$ Consultative Document. HMSO: London.

Department of Health and Social Security (1977). The Way Forward. HMSO: London.

Department of Health and Social Security (1978). A Happier Old Age. A Discussion Document on Elderly People in our Society. HMSO: London.

Hunt, A. (1978). The Elderly at Home: A Study of People Aged Sixty-five and over Living in the Community in England in 1976. HMSO: London.

Office of Population Censuses and Surveys (1977). Population Projections 1974-2014. HMSO: London. 